\title{
Exploring an Interprofessional Staff-Training Model: Application for Teachers and Therapists Working with Children Diagnosed with Autism
}

\author{
Lina Slim 1,* and Genevieve Pinto Zipp 2,* \\ ${ }^{1}$ Founding Executive Director of Educational and Behavioral Services, ASAP - A Step Ahead Program, LLC, \\ 33 Joss Way, Millington, New Jersey 07946, USA \\ ${ }^{2}$ Professor, Department of Interprofessional Health Sciences and Health Administration, Seton Hall \\ University, School of Health and Medical Sciences, 400 South Orange Ave, South Orange New Jersey \\ 07079, USA
}

\begin{abstract}
Increased prevalence of Autism Spectrum Disorder (ASD) has generated higher special needs enrollment in schools requiring teachers and therapists to acquire, incorporate and implement specialized strategies needed to address unique educational and behavioral challenges facing children diagnosed with ASD. Budget cuts have generated a shortage of qualified professionals with expertise in autism interventions. Currently, staff training is minimal, ineffective or lacking on how to do acquire these skills. More effective staff training may provide an avenue for addressing this shortage. This study investigates the impact that an Interprofessional Staff Training Procedure (STP), consisting of Video Self-Monitoring (VSM), Performance Feedback (PF) and Reflection (R) with and without Mentoring has on sustained and generalized teacher performance on two Dependent Variables - application of the Learn Unit (LU) and Rate of Effective Instruction (ROI). An exploratory study was conducted with 10 female teachers instructing 3-5 year old autistic children in two private schools utilizing principles of Applied Behavior Analysis. Teacher performance on LU and ROI was evaluated after: Phase 1 - 2-hour workshop; Phase 2 - training period using STP with and without Mentoring and Phase 3 follow-up period when STP and Mentoring are removed. While the STP appeared to enhance teacher performance and sustainability of procedural integrity, the greatest and most consistent improvement in performance was observed among teachers who received STP plus Mentoring as opposed to STP alone. Findings revealed that adding Mentoring to an existing STP appears to enhance teacher performance and Procedural Integrity with sustainable outcome.
\end{abstract}

Keywords: Training, mentoring, Autism Spectrum Disorders, teacher training, video self-monitoring.

\section{BACKGROUND}

The increased prevalence and complexity of ASD requires special educators and related service providers to develop and implement evidence-based intensive behavioral interventions strategies as part of their classroom instructions [1-2]. The Centers for Disease and Control (CDC) notes that 1 in 68 children nationally are diagnosed with ASD. The surveillance summaries report of 2010 found $31 \%$ of children with ASD classified as having IQ scores in the range of intellectual disabilities, $23 \%$ at borderline, and $46 \%$ at average or above average of a range of intellectual disability [3]. The report also identified that race and ethnicity were key factors impacting the proportion of children classified with ASD (48\% of non-Hispanic black children with ASD had intellectual disability, $38 \%$ of Hispanic children and $25 \%$ of non-Hispanic white). Today's special educators must be equipped with the tools necessary to meet not only the behavioral needs

*Address correspondence to this author at the Founding Executive Director of Educational and Behavioral Services, ASAP - A Step Ahead Program, LLC, 33 Joss Way, Millington, New Jersey 07946, USA; Tel: 908-313-5235;

Fax: 908-542-0001; E-mail: I.slim-topdjian@asapprogram.org

Department of Interprofessional Health Sciences and Health Administration, Seton Hall University, School of Health and Medical Sciences, 400 South Orange Ave, South Orange New Jersey 07079, USA; Tel: 973-275-2457;

Fax:973-275-2171; E-mail: Genevieve.Zipp@shu.edu of children with ASD but the identified cultural diversity and intellectual disabilities as stated in the 2014 report.

Traditionally, in the educational environment teachers are the sole providers of academic instruction. However, when working with this unique population it is the collaboration between educators and therapists that create a cohesive, comprehensive and individualized educational program that meets the complex needs of children with ASD. Two critical components in the management of children with ASD are (1) staff training [4], and (2) interprofessional collaborative practice (IPP) [5]. A barrier impacting the implementation of interprofessional intervention strategies has been limited school budgets, which has significantly reduced staff training opportunities within the educational environment [6-7]. Recent studies have shown that teacher and therapist training is not only minimal but also ineffective at times and often lacks standardization [7-8]. More effective interprofessional staff training may provide an avenue for addressing these barriers [4][89].

The literature speaks to different staff training procedures (STP) that lead to positive improvement in teaching staff performance (TSP) and procedural 
integrity (PI) [10-12]. In the literature four STP have been identified as being effective: (1) video selfmonitoring (VSM), whereby an individual creates a video tape of him/herself performing a target behavior or function then reviews it to analyze and rate performance on the application of behavioral guidelines objectives and procedural integrity [13-14]; (2) selfevaluation/self-monitoring [15], defined as a selfregulated learning procedure that involves having an individual compare his/her performance against a standard or norm and making changes in his/her learning experience based on his/her informed perceptions of the quality of expected performance [16]; (3) performance feedback (PF) defined as the process of monitoring and evaluating target behaviors against objective benchmarks and providing corrective feedback to the individual regarding these behaviors through a frequent, immediate and structured monitoring process [15-21]; (4) reflection (R) which involves problem solving and self-analysis of one's behavior [22-27]. While the STP have been effective in changing teacher performance several limitations have been noted in the studies including small sample size, limited educational setting and skill set taught, and a lack of an established and standardized staff training framework.

The aim of this study was to investigate the impact of STP consisting of VSM, PF and R, with and without mentoring teacher performance as measured by two dependent variables - (1) application of the learn unit (LU) an interlocking three-term contingency that consists of the teaching staff's antecedent, the student's response, and the consequence [28-30]; and (2) rate of effective instruction (ROI) which refers to both rates of correct and incorrect LU presentation per minute and reflects on the teacher's effectiveness of instruction [31-32]. Practical and theoretical implications for interprofessional practice are discussed.

\section{METHODS}

\section{Subjects and Setting}

Ten female English speaking teachers with a mean age of 35 years $(S D=8.8)$ instructed seven 3-5 year old children diagnosed with ASD, who attended two private schools utilizing principles of applied behavior analysis participated in this exploratory study. All teachers possessed minimally a baccalaureate degree, specifically seven held a baccalaureate degree, two held a master's degree, and one held a jurisprudence degree. In terms of work experience instructing students with autism, three had over ten years of experience, two had between six and 10 years of experience, four had between one and five years of experience, with only one having less than one year of experience.

\section{Variables}

The two dependent variables (DV) in this study consisting of (1) application of the LU and (2) ROI, were measured against the independent variable (IV) of PTR/mentoring.

\section{Instrument and Material}

The Teacher Performance Rating and Accuracy Scale (TPRA) - Abbreviated Version (Appendix A) was used to measure teacher's performance on the application of LU and the ROI [28, 34-35]. A Canon PowerShot SX280 12 MP digital camera was used to record the teacher-student interactions, which were then transferred via a USB connector onto a laptop for analysis.

\section{Procedure and Design}

The research study design employed was exploratory and descriptive in nature. Single-subject

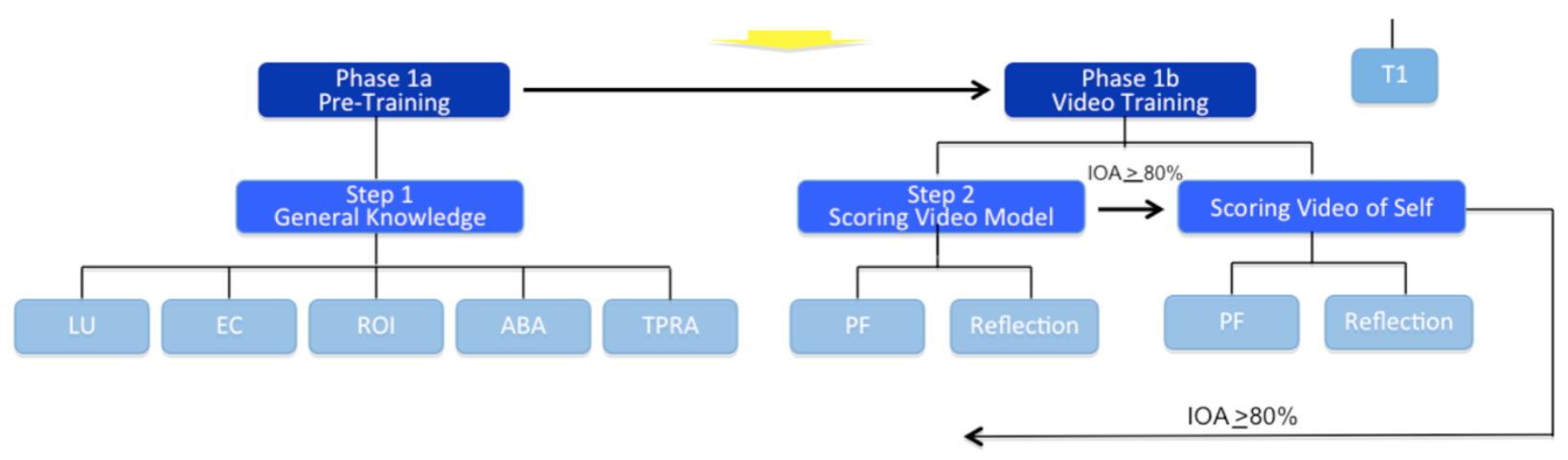

Figure 1: Diagram of Phase 1 - Pre-Training (Workshop). 
data analysis was used to evaluate changes between pre- and posttest measures.

The study was comprised of three phases:

Phase 1: Pre-training (workshop) in which teachers attended a two-hour training workshop on the $\mathrm{LU}$ and ROI, VSM, and scoring procedures. Figure 1 illustrates the steps of Phase 1. Teachers who performed with $80 \%$ accuracy, over two occasions, on the scoring of $\mathrm{LU}$ implementation and rate of instruction were included in phase 2 of the study.

Phase 2: Post-training reinforcement (skill acquisition) in which the teachers were randomly assigned to either the intervention or the control group. Figure 2 illustrates the steps of Phase 2.

Each teacher in the intervention group was videotaped instructing a student in the classroom for the duration of three minutes. While a broad range was noted in the literature from one minute to 15 minutes [14][19][33][36-40], the authors chose a duration of three minutes for observation, as it provided a meaningful and non-disruptive presence within the classroom environment. Each videotaped session was analyzed by the independent expert rater/observer on that same day. Following the videotaped session, a performance feedback process was conducted by having each teacher view her own-videotaped performance, score and rate her teaching performance using the TPRA form as taught in Phase 1. The teachers' scoring happened in the presence of the mentor who provided feedback and mentoring on the performance outcome following a predetermined formal script (Appendix B, C). Strengths and recommendations were identified by both the teachers and the mentor and were written down. After the performance feedback and mentoring session, the teachers completed a brief written reflection journal responding to three written prompts (Appendix D). Phase 2 took approximately 15 minute per teacher per day and was repeated over four consecutive days. Each teacher in the control group followed the same process, however, they did not receive performance feedback and mentoring on the performance outcome. Strengths and recommendations were identified by the teacher alone and were written down by the teachers only, following a predetermined script.

Phase 3: Follow-up (sustainability) in which all participants were grouped into one group and were videotaped by for a 3-minute teacher-student

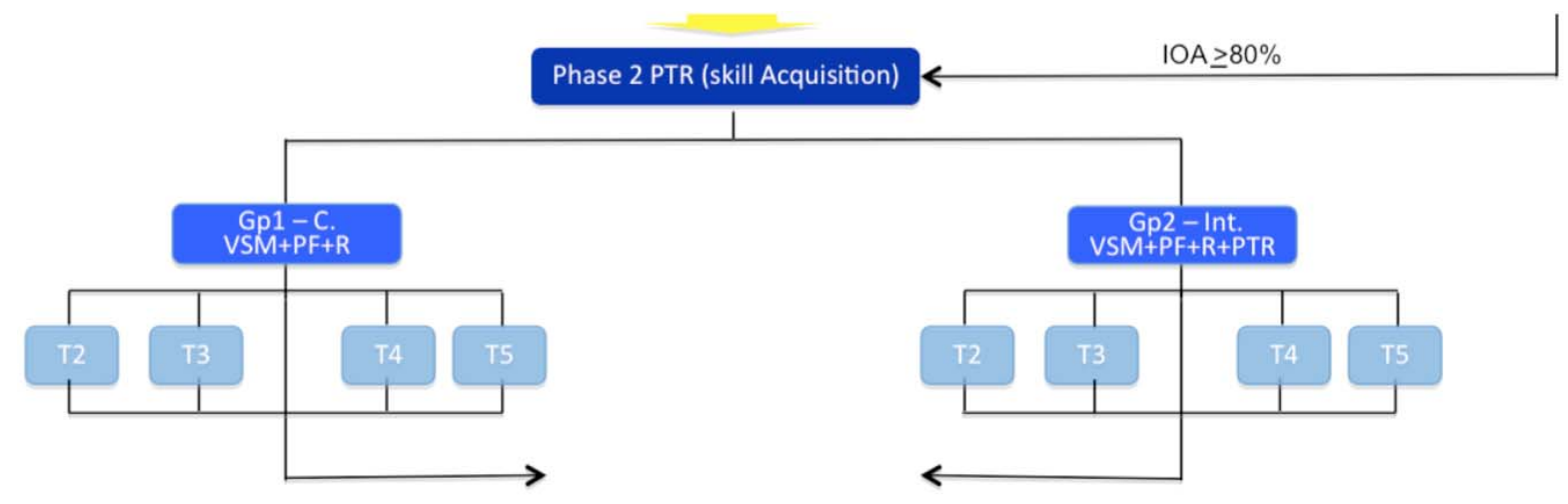

Figure 2: Diagram of Phase 2 - Post-Training Reinforcement (Skill Acquisition).

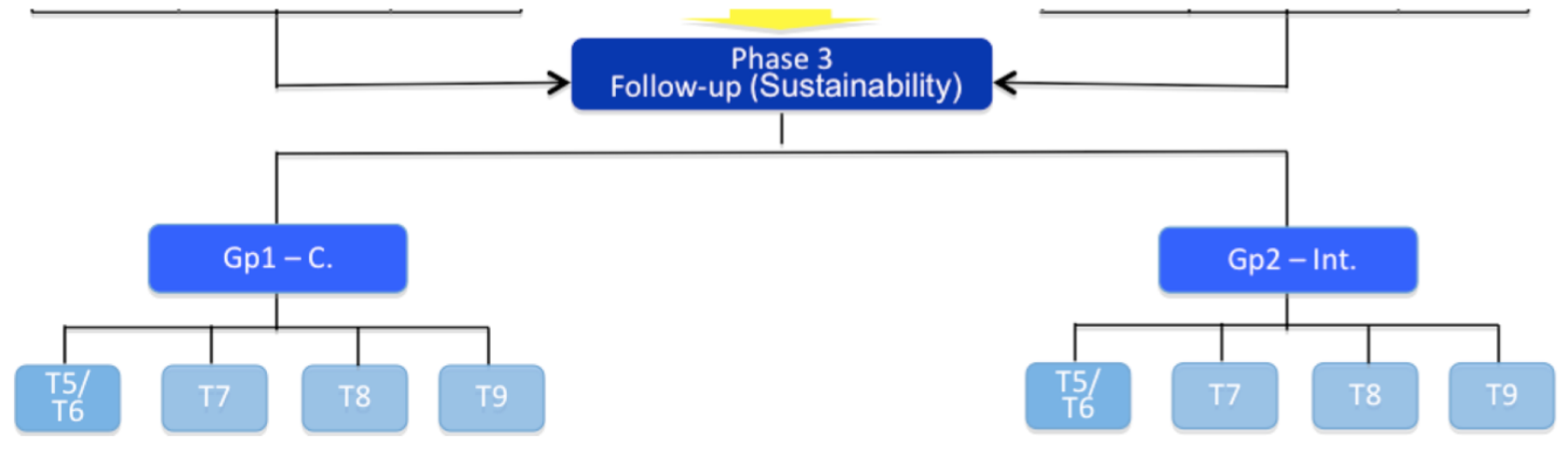

Figure 3: Diagram of Phase 3 - Follow-up (Sustainability). 


\section{Sequence of LU/EC Procedure Formula}

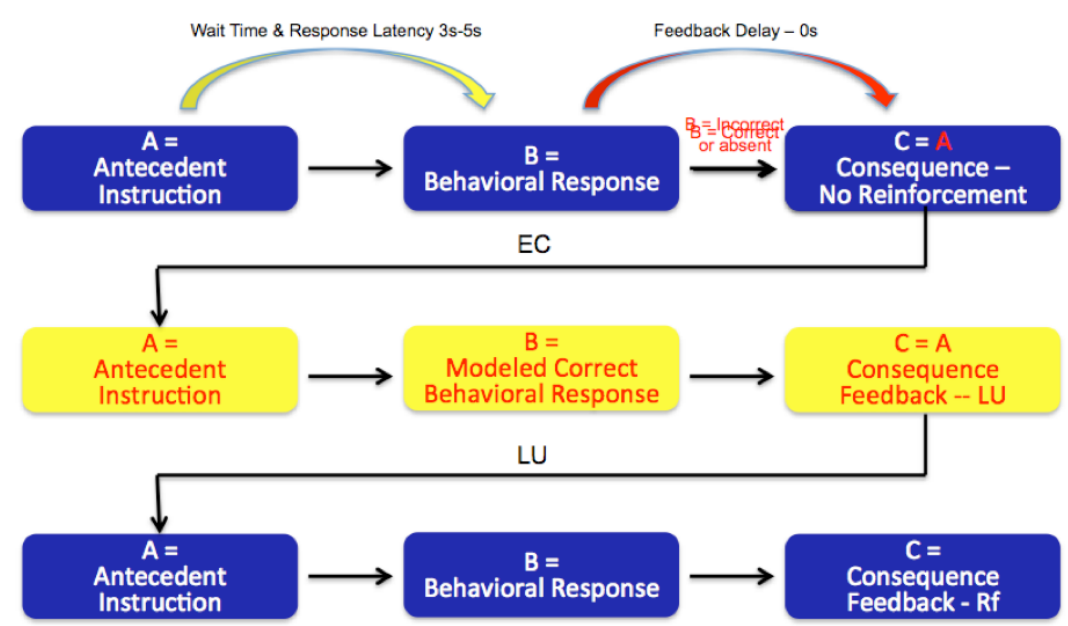

Figure 4: Diagram of a sequence of LU/EC procedure formula.

interaction once every four days over the period of 21 days. The independent rater/observer scored the teachers' teaching performance and the teachers were not required to score their performance and did not complete a reflection journal. Figure 3 illustrates the steps of Phase 3.

\section{Data Analysis}

Video self-monitoring and self recording was used to score teacher-student interactions following the teaching procedure for the implementation of a LU (Figure 4).
Simple algorithmic computations based on the literature [28] were used to compute the scores for LU percent accuracy and ROI. The diagram of the data collection procedure is illustrated in Figure 5. Figure 6 illustrates the design and data analysis procedures in all three phases of the study.

\section{RESULTS}

Figure 7 illustrated the average scores in the teacher's performance of $\mathrm{LU}$ and $\mathrm{ROI}$ for the intervention and control groups in all three phases of the study.

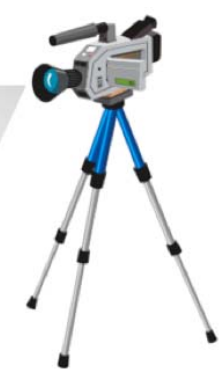

Control Gp. (Without PTR)
Experimental Gp. (With PTR)
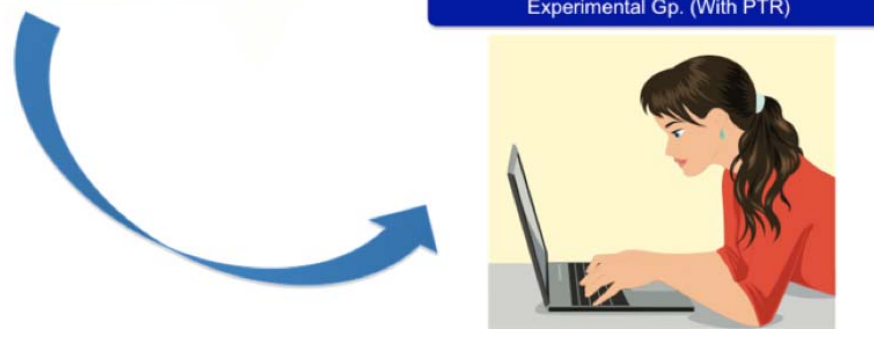

Figure 5: Diagram of data collection procedure - Phase 2. 


\section{Research Design - Exploratory Study}

Phase 1: Pre-Training (Workshop)

Pre-Posttest / Single - Case Study Analysis

Data Analysis: Pre-Posttest. 1 IV (Workshop), 1 group, 2 DV (LU and ROI)

\section{Phase 2: Post Training Reinforcement (Skill Acquisition)}

$$
\text { Single - Case Study Analysis }
$$

Data Analysis: Repeated Pre-Posttest measures. IV (PTR [Control and Intervention]), $2 \mathrm{DV}$ (LU and ROI); Determine directionality of effect of Mentoring (PTR) on LU and ROI

\section{Phase 3: Follow-up (Sustainability)}

Single - Case Study Analysis

Data Analysis: Repeated Pre-Posttest measures. IV (PTR [Control and Intervention]), $2 \mathrm{DV}$ (LU and ROI); Determine directionality of effect of Mentoring (PTR) on PI

Figure 6: Design and data analysis - Phases 1,2, and 3.

\section{Teacher Performance of LU and ROI for the Intervention and Control Groups (Ave.)}

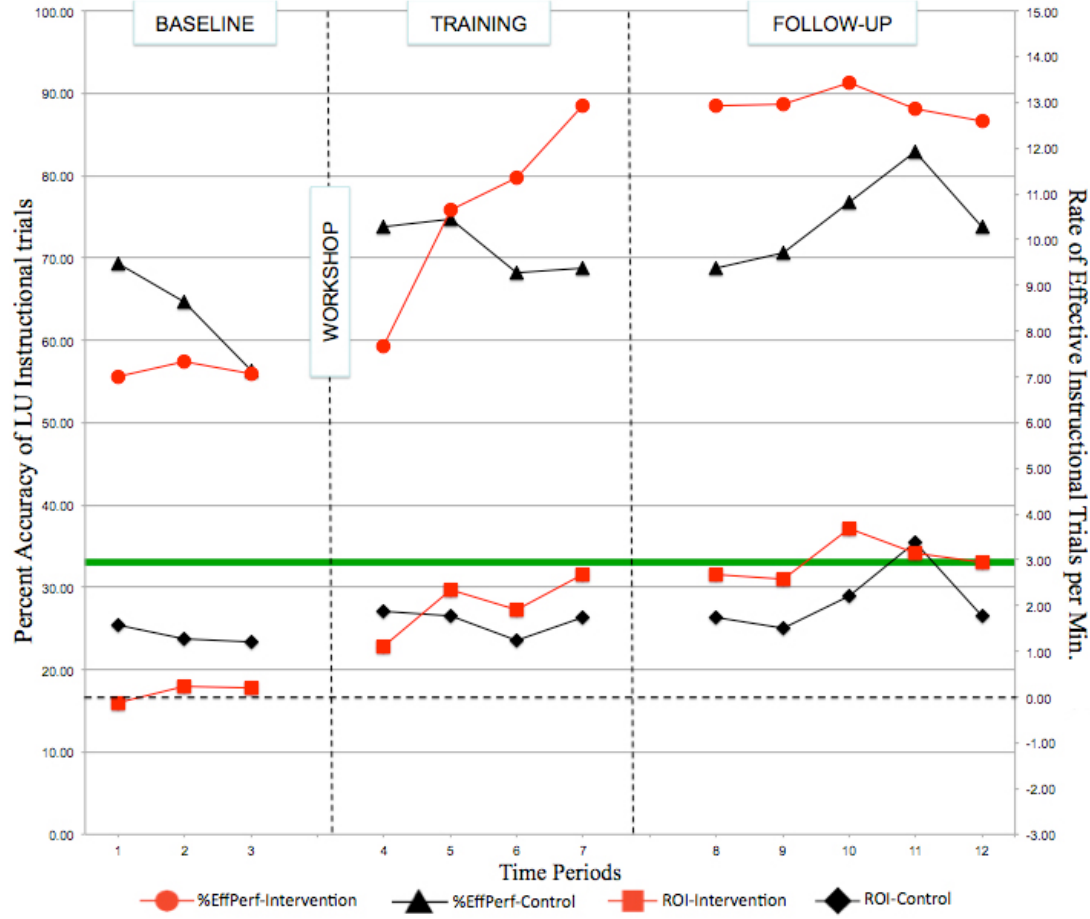

Figure 7: The average scores in the teacher's performance of LU and ROI for the intervention and control groups in all three phases of the study.

\section{Phase 1 - Pre-Training (Workshop Only)}

Only $50 \%$ of the participants showed an increase in the effective performance of LU implementation ranging from $7.1 \%$ increase to $17.7 \%$ increase. Only $60 \%$ of the participants showed an increase in ROI after attending the pre-training workshop. Table 1 depicts pre- and posttest average scores in the teacher's effective performance of LU implementation and $\mathrm{ROI}$ for the control and the intervention groups in Phase 1 of the study.

\section{Phase 2 - Post-Training Reinforcement with or without Mentoring (Skill Acquisition)}

Upon averaging the scores over the four days, STP with mentoring was observed to lead to the greatest improvement with most consistent performance among teachers. Interestingly, four of the five participants 
Table 1: Pre- and Posttest Average Percent Scores in the Teacher's Effective Performance of LU Implementation and ROI for the Control and Intervention Groups in Phase 1 of the Study

\begin{tabular}{|c|c|c|c|c|}
\hline \multirow{2}{*}{$\begin{array}{c}\text { TEACHERS } \\
\text { TC and TI }\end{array}$} & \multicolumn{2}{|c|}{ PHASE 1 - LU } & \multicolumn{2}{|c|}{ PHASE 1 - ROI } \\
\hline & Pretest & Posttest & Pretest & Posttest \\
\hline Control Gp. & Sessions 1, 2, 3 & Session 4 & Sessions 1, 2, 3 & Session 4 \\
\hline TC-1 & $56 \%$ & $60 \%$ & 0.5 & 0.4 \\
\hline TC-2 & $60 \%$ & $58 \%$ & 1 & 2.6 \\
\hline TC-3 & $48 \%$ & $55 \%$ & 1.4 & 0.3 \\
\hline TC-4 & $73 \%$ & $80 \%$ & 1.1 & 2.7 \\
\hline TC-5 & $80 \%$ & $87 \%$ & 2.8 & 3.4 \\
\hline \multicolumn{5}{|l|}{ Interv. Gp. } \\
\hline TI-1 & $79 \%$ & $100 \%$ & 1.5 & 3.6 \\
\hline TI-2 & $69 \%$ & $54 \%$ & 2.4 & 0.3 \\
\hline $\mathrm{TI}-3$ & $72 \%$ & $50 \%$ & 1.8 & 0 \\
\hline $\mathrm{TI}-4$ & $26 \%$ & $72 \%$ & -4 & 2.67 \\
\hline TI-5 & $36 \%$ & $20 \%$ & -1.3 & -1 \\
\hline
\end{tabular}

demonstrated increased scores above $80 \%$, which were maintained over 21 days, with a percent increase ranging from $5.1 \%$ increase to $203.1 \%$; Whereas two of the five participant following STP without mentoring demonstrated increased scores above $80 \%$, which were maintained over 21 days, with a percent increase ranging from $10 \%$ to $46.6 \%$. Table 2 depicts the mean percent LU scores of the teacher's effective performance for the control and intervention groups in all phases of the study.

Moreover, four of the five participants who engaged in the STP with mentoring demonstrated increased scores in $\mathrm{ROI}$ ranging from 0.7 to 4 point difference; Whereas following STP without mentoring three of the five participants showed an increase in ROI scores ranging from 0.4 to 1.2 point difference. Table 3 depicts the mean $\mathrm{ROI}$ per minute scores in the teacher's performance for the control and the intervention groups in al three phases of the study. Overall, STP with mentoring was also observed to enhance teacher performance and procedural Integrity with sustainable outcomes.

\section{Phase 3 - 21-Day follow up (Sustainability)}

Procedural integrity of $\mathrm{LU}$ presentation and $\mathrm{ROI}$ improved over time with mentoring with average scores above $80 \%$ in effective performance of LU implementation $(5 / 5$ teachers who received STP with

Table 2: Mean Percent LU Scores of the Teacher's Effective Performance for the Control and Intervention Groups in all Phases of the Study

\begin{tabular}{|c|c|c|c|}
\hline TEACHERS & PHASE 1 & PHASE 2 & PHASE 3 \\
\hline Control Gp. & Sessions 1,2,3 & Sessions 4,5,6,7 & Sessions 8,9,10,11,12 \\
\hline \hline TC-1 & $56 \%$ & $70 \%$ & $75 \%$ \\
\hline TC-2 & $60 \%$ & $88 \%$ & $70 \%$ \\
\hline TC-3 & $48 \%$ & $49 \%$ & $71 \%$ \\
\hline TC-4 & $73 \%$ & $61 \%$ & $86 \%$ \\
\hline TC-5 & $80 \%$ & $88 \%$ & \multicolumn{2}{|c|}{} \\
\hline Interv. Gp. & \multicolumn{2}{|c|}{$96 \%$} \\
\hline Tl-1 & $79 \%$ & $83 \%$ & $81 \%$ \\
\hline Tl-2 & $69 \%$ & $69 \%$ & $89 \%$ \\
\hline Tl-3 & $72 \%$ & $79 \%$ & $85 \%$ \\
\hline Tl-4 & $26 \%$ & $79 \%$ & $94 \%$ \\
\hline Tl-5 & $36 \%$ & $66 \%$ & \\
\hline
\end{tabular}


Table 3: Mean ROI Per Minute Scores in the Teacher's Performance for the Control and Intervention Groups in all Phases of the Study

\begin{tabular}{|c|c|c|c|}
\hline TEACHERS & PHASE 1 & PHASE 2 & PHASE 3 \\
\hline Control Gp. & Sessions 1,2,3 & Sessions 4,5,6,7 & Sessions 8,9,10,11,12 \\
\hline \hline TC-1 & 0.5 & 1.7 & 2.7 \\
\hline TC-2 & 1 & 2.2 & 2.6 \\
\hline TC-3 & 1.4 & 0.1 & 2.8 \\
\hline TC-4 & 1.1 & 1.1 & 2.9 \\
\hline TC-5 & 2.8 & 3.2 & 3.5 \\
\hline Interv. Gp. & \multicolumn{3}{|c|}{} \\
\hline Tl-1 & 1.5 & 2.3 & 2.9 \\
\hline TI-2 & 2.4 & 1.4 & 4.2 \\
\hline Tl-3 & 1.8 & 2.5 & 2.7 \\
\hline Tl-4 & -4 & 2.1 & 2.2 \\
\hline TI-5 & -1.3 & 1 & \\
\hline
\end{tabular}

mentoring vs. $2 / 5$ teachers who STP without mentoring), and average ROI scores above 2.9 (3/5 teachers who received STP with mentoring vs. 1/5 teacher who STP without mentoring). STP without mentoring was observed to lead to greater variability in performance although learning was observed while engaging in the STP. STP with Mentoring was observed to lead to consistent and sustained higher scores then without Mentoring. (See Tables 2 and 3).

\section{SOCIAL ACCEPTIBILITY}

Qualitative data obtained daily during Phase 2 of the study provided insight regarding the teachers' perception of the experience. Specifically, the teachers were asked to complete a reflection journal answering 3 prompts, reflecting on their observed behavioral performance, their next steps in providing corrective measures and solutions, and their impressions

Table 4: Examples of Participants' Comments on the Study Staff Training Model

\begin{tabular}{|c|}
\hline $\begin{array}{l}\text { Learn Unit (LU) } \\
\text { "Improve on what response should be expected from the learner" } \\
\text { "Make expectations more clear" } \\
\text { "Ensure the child is attending before providing instruction" } \\
\text { "Give a variety of praise for correct mastered targets" } \\
\text { "Implement the error correction procedure when the child errs" }\end{array}$ \\
\hline $\begin{array}{l}\text { Rate of Effective Instruction (ROI) } \\
\text { "Increase rate of correct error correction procedure" } \\
\text { "Increase pacing to allow less time for student to engage in stereotypy" } \\
\text { "Be more aware of pace of Instruction" } \\
\text { "Change the pace of my instruction" }\end{array}$ \\
\hline $\begin{array}{l}\text { Mentoring } \\
\text { "Helpful to review together for insight \& feedback" } \\
\text { "Thought and opinions given by mentor were professional \& helpful" } \\
\text { "Good to have a non-team member review your work" }\end{array}$ \\
\hline $\begin{array}{l}\text { Video } \\
\text { "Helpful to point out areas to be improved \& corrected" } \\
\text { "Shows what we do vs. what we think we do" } \\
\text { "Makes my sessions more effective" }\end{array}$ \\
\hline $\begin{array}{l}\text { Staff Training Model } \\
\text { "A quality one, based on my observations of positive results in the child's responses \& my instruction" } \\
\text { "Able to be implemented across any environment, task, instructor or learner" } \\
\text { "Offers me an opportunity to be accountable for my behavior and room for improvement" } \\
\text { "Performance feedback was well received" } \\
\text { "Very Inspiring, Insightful and Rewarding" } \\
\text { "Effective" }\end{array}$ \\
\hline
\end{tabular}


regarding the interprofessional staff training model implemented. This reflective exercise speaks to the notion of mindfulness [22].

Table 4 depicts the teachers' comments that were grouped per categories. It is interesting to note that the comments reflect the LU and ROI studied. Overall, the teachers stated that the staff training model was "Very inspiring, insightful, rewarding and effective" and that mentoring was "Helpful", "Professionally and respectfully handled", and that is was "Good to have a non-team member review your work".

\section{DISCUSSION AND CONCLUSION}

The study findings support mentoring as a complement to existing interprofessional staff training as evidenced by enhanced teacher performance and procedural integrity with sustainable outcomes. These findings extend the interprofessional research findings of Lerman et al.'s [40] and Pelletier et al. [14]. The authors of the current study suggest that providing mentoring to staff training for those teachers that demonstrate inconsistent performance may be beneficial in supporting and building the teaching foundation needed to promote greater consistency in their performance and procedural integrity sustained over time. Finally, the positive teacher perceptions noted, further support the feasibility and applicability of implementing a mentored interprofessional stafftraining model.

The interprofessional staff training model in this study incorporates the underpinnings of interprofessional competencies required in the implementation of interprofessional learning approaches, in support of interprofessional education (IPE), interprofessional collaborative practice (IPP) and interprofessional teamwork. Specifically, this interprofessional staff training model is learner centered approach as it is based on a continuum of self-evaluation and reflection processes; learner-mentor relationship focused, with operationally defined and clearly delineated expectations and objectives to match the learner's skill levels and needs; process oriented as it adheres to objective behavioral guidelines the outcome of which is assessed on an ongoing basis and paired with modifications to match the professional's learning; integrated across the learning continuum and educational strategies and matched to the learner's educational and skill levels, and embeds an ongoing self-assessment, self-reflective component; sensitive to the environmental contingencies, the external (i.e., resources) and internal (i.e., emotional) needs of the learner; transferrable and generalizable across settings, teachers, and teaching objectives and curricula, and applicable across professions and disciplines; and it is outcome driven following objectively defined guidelines and benchmarks.

\section{CLINICAL RELEVANCE}

For teachers seeking to implement evidence-based strategies to address the complex needs of children with ASD, interprofessional mentoring associated with the interprofessional staff training model provides additional assistance, emotional support and technical tools needed. Additionally, the self-reflection required by each teacher within this interprofessional staff training model promotes active learning and critical thinking that helps the teacher manage the learning environment to meet each student's needs.

This interprofessional staff training model provides a venue for educators to engage in experiential learning opportunities that foster the development of effective objective teaching approaches as well as qualitative personal skills essential for effective collaboration among educators to ascertain the highest quality of learner centered care. Furthermore, this interprofessional staff training model provides an effective and supportive venue through which two or more professions or disciplines collaboratively learn about, from and with each other to improve the learner's educational and behavioral outcomes.

\section{LIMITATIONS}

As with any study there are limitations. The primary limitations of this study include sample size, the study design, sampling method and duration of the training protocol.

\section{FUTURE DIRECTION}

While this study was only exploratory in nature it provides a platform for future research investigating interprofessional staff training protocols for teachers working with children diagnosed with ASD. While all students with ASD may not have intellectual disabilities often times students with intellectual disabilities face additional challenges in their educational programming which may include attentional, behavioral, social and communication problems. These challenges impact the teacher-student and student-student interactions and such requires that teachers acquire specialized skills and instructional strategies to meet each student's 
needs. The interprofessional staff training model provides teachers with a self-monitoring strategy that enables them to assess the educational environment and their performance within it as they seek to address their student's needs. Unique to this model is its interprofessional component, which enables professionals to learn with and from each other as they engage in self-monitoring and performance feedback opportunities with mentoring.

The interprofessional staff training model implemented in this research study is preliminary and should be applied to a variety of populations, settings and across diverse educational strategies in order to ascertain the efficacy of the model and to further develop more efficacious and sustainable outcomes. The well being, health and education of our future generation depends on the ability of our educators and mentors to implement evidence-based interprofessional intervention approaches and strategies to address health and behavioral problems in the face of economic adversity within our educational systems.

\section{ACKNOWLEDGEMENTS}

I am eternally grateful for the support and encouragement that I have received from all the people in my life. I would like to thank the schools that have graciously welcomed me to conduct my dissertation study at their facility. I would also like to thank all the teachers who volunteered and who embraced the new learning presented, and all the families who kindly allowed their children to participate in the study. I would like to thank Dr. Tom Walk, Prof. Sethi, and Dr. Cabell for all the teachings of statistics and design, and for your generous support throughout my journey. I would like to thank my dissertation committee, Dr. Deborah Deluca, Dr. Terrence Cahill, and Dr. Genevieve Pinto Zipp, who provided me with endless and tireless support, patience, valuable mentorship and direction in the completion of my dissertation. Most importantly, I would like to thank my friends and family for their endless love, support, care and always believing in me.

\section{APPENDIX A:}

Teacher Performance Rate and Accuracy Scale - Abbreviated Version (TPRA)

\begin{tabular}{|c|c|c|c|c|c|c|c|c|c|c|c|c|}
\hline \multirow{2}{*}{\begin{tabular}{|c|} 
Objectives \\
LU
\end{tabular}} & \multicolumn{5}{|c|}{ Learn Unit } & \multicolumn{5}{|c|}{ Error Correction } & \multirow[b]{2}{*}{ EC } & \multirow[b]{2}{*}{ Comments } \\
\hline & $\bar{A}$ & $B$ & $\mathrm{R} / \mathrm{C}$ & LU-R & LU-C & $\bar{A}$ & PB & No-R & $\bar{D}$ & New-LU & & \\
\hline 1 & & & & & & & & & & & & Recommendations \\
\hline 2 & & & & & & & & & & & & \\
\hline 3 & & & & & & & & & & & & \\
\hline 4 & & & & & & & & & & & & \\
\hline 5 & & & & & & & & & & & & \\
\hline 6 & & & & & & & & & & & & \\
\hline 7 & & & & & & & & & & & & \\
\hline 8 & & & & & & & & & & & & \\
\hline 9 & & & & & & & & & & & & \\
\hline 10 & & & & & & & & & & & & \\
\hline 11 & & & & & & & & & & & & Strengths \\
\hline 12 & & & & & & & & & & & & \\
\hline 13 & & & & & & & & & & & & \\
\hline 14 & & & & & & & & & & & & \\
\hline 15 & & & & & & & & & & & & \\
\hline Correct\# & & & & & & & & & & & & $\begin{array}{l}\text { LU\% acc. }= \\
\text { LUc } \times 100\end{array}$ \\
\hline Error\# & & & & & & & & & & & & $(\mathrm{LUc}+\mathrm{LUe})$ \\
\hline$\%$ Correct & & & & & & & & & & & & $\begin{array}{c}\text { ROI = } \\
(L U c-L U e)\end{array}$ \\
\hline \%Error & & & & & & & & & & & & Duration (min.) \\
\hline
\end{tabular}

(Greer, 2002; Greer, et al. 2008)

$\mathbf{L U}=$ Learn Unit $/ \mathbf{I T}=$ Instructional Trial $/ \mathbf{A}=$ Antecedent $/ \mathbf{B}=$ Student Behavior $/ \mathbf{+}=$ Correct $/$ - = Error or Absence $/ \mathbf{R}=$ Reinforcement $/ \mathbf{C}=$ Correction $/ \mathbf{P B}=$ Prompted Behavior $/ \mathbf{D}=$ Distractor(s) 


\section{APPENDIX B}

\section{Performance Feedback Script and Score Form for LU/EC}

Answer with Yes or No to the following questions:

1. Did you obtain the student's Attention before presenting the antecedent $\quad \square$ Yes $\square$ No

2. Did you present flawless Antecedents, including written or vocal stimuli $\quad \square$ Yes $\square$ No

3. Did you wait 3 seconds for the student to initiate a response $\quad \square$ Yes $\square$ No

4. Did you immediately present Reinforcement after correct responses $\quad \square$ Yes $\quad \square$ No

5. Did you follow the Error Correction procedure after incorrect responses $\quad \square$ Yes $\quad \square$ No

1) Did you immediately give a Correction by presenting the Antecedent again, modeling the correct response, and ensuring that students emit the correct response $\square$ Yes $\square$ No

2) Did you abstain from reinforcing the corrected response

$\square$ Yes $\square$ No

3) Did you immediately introduce the next Learn Unit after the modeled corrected response

$\square$ Yes $\square$ No

6. Did you move quickly to the next Learn Unit

$\square$ Yes $\square$ No

7. Did you continue this sequence until the predetermined number of $L U$ is presented

$\square$ Yes $\square$ No

Performance Feedback Score:

Total: $\_/ 10=\ldots$ acc.

\section{APPENDIX C}

\section{Video Performance Feedback}

\section{Sample List of Strengths and Needs For Improvement Strengths}

\section{Sample List of Strengths:}

1. Fast-Paced Instruction

2. High Energy and Momentum

3. High and Appropriate Praise

4. Social Praise

5. Behavior-Specific Praise

6. Interspersal of Instructional Trials and Learn Units

7. Preference Choice Assessment

8. Use of Manding with Autoclitics

9. Increased Incidental Learning Opportunities 


\section{Improvements Opportunities}

1. Establish attending prior to presenting antecedent in order to avoid unnecessary repetitions of antecedents

2. Apply the Error Correction procedure across settings and programs (Learn Units and Incidentals)

3. Data collection needs to be ongoing

4. Intersperse mastered when implementing the Error Correction procedure

5. Use behavior-specific praise

6. Avoid subjective praise such as "Good boy" or "You're so smart" etc.

7. Identify the prompt levels for each program and fade within the session

8. Use time delay to foster independence

9. Use full sentences to match the learner's verbal behavior

10. Praise incidental requests (i.e., "look...")

11. Avoid non-verbal gestures of discontent when the incorrect response is provided.

\section{APPENDIX C}

\section{Video Performance Feedback}

\section{Sample List of Strengths and Needs For Improvement Strengths (Continued)}

1. Limit the number of material present in the learner's visual field to target items.

2. Using a reinforce book or a board stating the reinforcer to be earned after a certain number of Instructional trials or time period may promote expanding is community of reinforcers.

3. Use of polite responses: "Yes please" "No Thank you"; "Give me a bead please"

You may also incorporate: "[name of therapist/teacher] give me the [item] please" followed by "Thank you"

4. Provide a variety of verbal behavior that effects a similar outcome: "May I have ---.." Or "Can I have the --please", "I want the ----- please"

5. When Learner mands independently follow by natural verbal responding "sure! Here you go" followed by having him reciprocate with "Thank you"

6. Instead of tapping your index finger on your nose prompting Learner to look at you either interrupt his activity by gently placing your hand on his hands and waiting or combine with a static GP to your eyes.

7. Limit the number of items in an activity in order to teach appropriate play sequence and do so using either a forward, backward or total task approach (i.e., stringing beads, stacking rings/blocks, puzzles, placing items in a container etc.)

8. Identify your own verbal behavior when teaching the learner in order not to create confusion: instead of "Give me string" followed by "Give me beads" followed by "Give me all the beads" chose one verbal statement you would like him to learn, understand and use such as "May I have the beads, please". You can teach the quantity concept "All" in parallel but under a structured task. 
9. Learner has verbal behavior that allows him to start a reading program and using textual prompts in conjunction with verbal prompts.

10. When he asks for a reinforcer select it (i.e. puppet)

11. When Learner emits vocal stereotypy in the form of non-contextual laughter apply Planned Ignoring and Redirecting instead of gaining attention to the behavior by stating, "You need to be quiet" (step back and assess the function of his behavior, and identify the intervention tactics).

\section{APPENDIX C}

\section{Video Performance Feedback}

\section{Sample List of Strengths and Needs For Improvement Strengths (Continued)}

1. Avoid negative responses such as "No, you don't put it in your mouth" "Don't put it in your face" (zoom ball) and instead demonstrate visually and verbally what you would do with the object at hand and praise appropriate manipulation (i.e. black putty)

2. The $S^{D}$ "Look at me" needs to be immediately followed by appropriate responding "eye contact" if not implement the EC procedure by using manual prompts (on the side of the face NOT under the chin lead)

3. During an expressive picture identification program the pictures used have the label on the back (no need to turn the photo to recognize the picture)

\section{APPENDIX D}

\section{Reflection Prompts}

Name:

Code\#:

Date:

Please answer the following questions as truthfully as possible:

1. Based on your video observations and analysis of your performance, your self-evaluation and answers in Appendix $\mathrm{B}$, and the Performance Feedback you received from the supervisor/mentor, what were the identified areas for improvement?

2. Based on your video observations and analysis of your performance, your self-evaluation and your answers in Appendix B and the Performance Feedback you received from the supervisor/mentor, what are the changes in your behavior that you will make for the next session?

3. Based on your observation and analysis of your performance, your self-evaluation and your answers in Appendix B, and the Performance Feedback you received from the supervisor/mentor, please reflect by providing your thoughts and opinions on the quality, effectiveness, value/meaningfulness, and functionality of this Staff-Training Model?

\section{REFERENCES}

[1] American Academy of Pediatrics. Understanding Autism Spectrum Disorders (ASDs): An Introduction. Elk Grove Village, IL: AAP; 2006, updated 2010.

[2] Croen, LA, Najjar, DV, Ray, T, Lotspeich, L, Bernal, P. A comparison of health care utilization and costs of children with and without autism spectrum disorders in a large groupmodel health plan. Pediatr 2006; 118: 1203-1211. http://dx.doi.org/10.1542/peds.2006-0127
[3] Baio, J. Autism and Developmental Disabilities Monitoring Network Surveillance Year 2010 Principal Investigators. Prevalence of Autism Spectrum Disorder Among Children Aged 8 Years - Autism and Developmental Disabilities Monitoring Network, 11 Sites, United States, 2010. Surveill Summ 2014; 63(2): 1-21.

[4] Kates-McElrath, K, Axelrod, S. Functional assessment in public schools: A tool for classroom teachers. In: Luce SC, Mandell DS, Mazefsky C, Seibert W, Eds. Autism in Pennsylvania, What lies ahead? Harrisburg: Pennsylvania 2008; p. 83-96. 
[5] Institute of Medicine Global Forum on Health Professions Education, Interprofessional Education for Collaborative Workshop Summary, May 2013

[6] Greer, RD, Yaun, L, Gautreaux, G. Effects of multiple exemplar instruction on transformation of stimulus function across written and vocal spelling responses by students with autism. Anal Verbal Behav 2005; 21: 99-116.

[7] Love JR, Carr JE, Almason SM, Petursdottir AI. Early and intensive behavioral intervention for autism: a survey of clinical practices. Res Autism Spectr Disord 2009; 21: 421428.

http://dx.doi.org/10.1016/j.rasd.2008.08.008

[8] Reid, DH, Parsons, MB, Lattimore, LP, Towery, DL, Reade, KK. Improving staff performance through clinician application of outcome management. Res Dev Disabil 2005; 26: 101116.

http://dx.doi.org/10.1016/j.ridd.2004.05.002

[9] Leblanc, LA, Gravina, N, Carr, JE (2009). Training issues unique to Autism Spectrum Disorders. In: Maston, JL, editor. Applied Behavior Analysis for Children with Autism Spectrum Disorders. Alabama: Springer Science and Business Media 2009; p. 225-235. http://dx.doi.org/10.1007/978-1-4419-0088-3 13

[10] Cooper, JO, Heron, TE, Heward, WL. Applied Behavior Analysis. Upper Saddle River, New Jersey. Pearson; 2007.

[11] Gresham, FM. Assessment of treatment integrity in school consultation and prereferral intervention. School Psych Rev 1989; 18:37-50.

[12] Hagermoser Sanetti, LM, Kratochwill, TR. Toward developing a science of treatment integrity: Introduction to special series. School Psych Rev 2009; 38(4): 445-459.

[13] Ahearn, W. Effect of video self-monitoring on procedural integrity. Behav Interv 2010; 25(4): 261-274.

http://dx.doi.org/10.1002/bin.316

[14] Pelletier, K, McNamara, B, Braga-Kenyon, P, Ahearn, WH. Effect of video self-monitoring on procedural integrity. Behav Interv 2010; 25(4): 261-274.

http://dx.doi.org/10.1002/bin.316

[15] Krause, UM, Stark, R. Reflection in example- and problembased learning: Effects of reflection prompts, feedback and cooperative learning. Eval Res Educ 2010; 23(4): 255-272. http://dx.doi.org/10.1080/09500790.2010.519024

[16] Kitsantas, A, Zimmerman, BJ. Enhancing self-regulation of practice: The influence of graphing and self-evaluative standards. Metacogn Learn 2006; 1: 201-212. http://dx.doi.org/10.1007/s11409-006-9000-7

[17] Reid, DH, Parsons, MB. Motivating Human Service Staff: Supervisory Strategies for Maximizing Work Effort and Work Enjoyment. 2nd ed. Morganton: North Carolina 2006.

[18] Codding, RS, Feinberg, AB, Dunn, EK, Pace, GM. Effects of immediate feedback on implementation of behavioral support plans. J Appl Behav Anal 2005; 38: 205-219. http://dx.doi.org/10.1901/jaba.2005.98-04

[19] Codding, RS, Livanis, A, Pace, GM, Vaca, L (2008). Using performance feedback to improve integrity of classwide behaviors plans: An investigation of observer reactivity, $\mathrm{J}$ of Appl Behav Anal 2008; 41: 417-422.

http://dx.doi.org/10.1901/jaba.2008.41-417

[20] Noell, GH, Witt, C, Slider, JS, Connell, JE, Gatti, SL, Williams, KL, Koenig, JL, Resetar, JL. Treatment implementation following behavioral consultation in schools: A comparison of three follow-up strategies. School Psych Rev 2005; 34(1): 87-106.

[21] Wilkinson, LA. Assessing treatment integrity in behavioral consultation. Int J Behav Consult Ther 2007; 3: 420-432. http://dx.doi.org/10.1037/h0100816
[22] Dewey, J. How We Think: A Restatement of Reflective Thinking to The Educative Process. Boston: MA, Health; 1933.

[23] Gartmeier, M, Kipfmueller, S, Heid, H, Gruber. Reflection and professional competence. A study at dynamic workplaces in the nursing sector. Res Rep 2008 No. 35. University of Regensburg, Institute of Education, Dept. Prof. Dr. Hans Gruber. In: Billett S, Harteis C, Eteläpelto A. Emerging perspectives on learning through work. London: Sage 2008; p. 131-147.

[24] Hetzner, S, Gartmeier, M, Heid, H, Gruber, H. Error Orientation and Reflection at Work. Vocation and Learning 2010; 4: 25-39. http://dx.doi.org/10.1007/s12186-010-9047-0

[25] Janssen, F, de Hullu, E, Tigelaar, D. Positive experiences as input for reflection by student teachers. Teach Teach: Theory Prac 2008; 14(2): 115-127. http://dx.doi.org/10.1080/13540600801965903

[26] Pedro, JY. Reflection in teacher education: Exploring preservice teachers' meanings of reflective practice. Reflect Prac 2005; 6(1): 49-66. http://dx.doi.org/10.1080/1462394042000326860

[27] Stoddard, SS. Reflective thinking within an art methods class for preservice elementary teachers. Hawaii International Conference on Education 2002.

[28] Greer, RD. Designing Teaching Strategies. An applied Behavior Analytic Systems Approach. Academic Press Educational Psychology Series. San Diego: CA; 2002.

[29] Greer, RD, Ross, ER. Verbal Behavior Analysis: Inducing and expanding New Capabilities in Children with Language Delays. Pearson Education, Inc. Boston: MA; 2008.

[30] Ross, DE, Wilson, CL, Goodman, J, Greer, RD. Using the learn unit as a measure of cost-effectiveness for professional development. J Educ Finance 2007.

[31] Greenwood, CR, Horton, BT, Utley, CA. Academic engagement: Current perspectives in research and practice. School Psych Rev 2002; 31(3): 328-349.

[32] Petscher, ES, Bailey, JS. Effects of training, prompting, and self-monitoring on staff behavior in a classroom for students with disabilities. J Appl Behav Anal 2006; 39: 215-226.

http://dx.doi.org/10.1901/jaba.2006.02-05

[33] Ross, DE, Singer-Dubek, J, Greer, RD. The Teacher Performance Rate and accuracy Scale (TPRA): Training as Evaluation. Educ Train Dev Disabil 2005; 40(4): 411-423.

[34] Leblanc, M, Ricciardi, JN, Luiselli, JK. Improving discrete trial instruction by paraprofessional staff through an abbreviated performance feedback intervention. Educ Treat Children 2005; 28: 76-82.

[35] Plavnick, JB, Ferreri, SJ, Maupin, AN. The effects of selfmonitoring on the procedural integrity of a behavioral intervention for young children with developmental disabilities. J Appl Behav Anal 2010; 43(2): 315-320. http://dx.doi.org/10.1901/jaba.2010.43-315

[36] Catania, CN, Almeida, D, Liu-Constant, B, DiGennaro-Reed, FD. Video modeling to train staff to implement discrete-trial instruction. J Appl Behav Anal 2009; 42: 387-392. http://dx.doi.org/10.1901/jaba.2009.42-387

[37] DiGennaro-Reed, FD, Codding, R, Catania, CN, Mahire, $\mathrm{H}$. The effects of video modeling on treatment integrity of behavioral interventions. J Appl Behav Anal 2010; 43: 291295.

http://dx.doi.org/10.1901/jaba.2010.43-291

[38] DiGennaro, F.D, Martens, BK, Kleinman, AE. A comparison of Performance feedback procedures on teachers' treatment implementation integrity and students' inappropriate behavior in special education classrooms. J Appl Behav Anal 2007; 40: 447-461.

http://dx.doi.org/10.1901/jaba.2007.40-447 
[39] Kate, E, Fiske, KE. Treatment integrity of school-based behavior analytic interventions: A review of the research. Behav Anal Pract 2008; 1(2): 19-25.
Lerman, DC, Tetrault, A, Hovanetz, A, Strobel, M, Garro, J. Further evaluation of a brief, intensive teacher-training model. J Appl Behav Anal 2008; 4(2): 243-248. http://dx.doi.org/10.1901/jaba.2008.41-243 